\title{
Avaliação em saúde: \\ reflexões inscritas no paradigma \\ sanitário contemporâneo
}

I 1 Glauce Dias da Costa, ${ }^{2}$ Rosângela Minardi Mitre Cotta, ${ }^{3}$ Sylvia do Carmo Castro Franceschini, ${ }^{4}$ Rodrigo Siqueira Batista, ${ }^{5}$ Andréia Patrícia Gomes, ${ }^{6}$ Poliana Cardoso

Martins, ${ }^{7}$ Maria de Lourdes da Silva Marques Ferreira I

Resumo: O presente estudo apresenta uma análise reflexiva dos métodos de avaliação em saúde em uma perspectiva do cuidado pensado e praticado segundo as necessidades dos usuários. Várias são as formas e abordagens dos processos avaliativos na busca de uma melhor apreensão do objeto de avaliação; neste contexto, a satisfação do usuário surge como um indicador de qualidade dos serviços de saúde, ligada à maior adequação e promoção de reais mudanças nas práticas de saúde. Diante da inovadora proposta do Programa Saúde da Família (PSF), baseado nos princípios de integralidade, cuidado à saúde e humanização, a participação e a satisfação do usuário surgem como elementos-chave na formulação de suas ações, possibilitando mudanças no modelo assistencial hegemônico, a saber, positivista, assistencialista e curativista. A presença do usuário no processo avaliativo irá permitir uma peculiar atuação, remodelando as práticas de saúde - quiçá tornando-as mais humanas, acolhedoras e, conseqüentemente, mais resolutivas..

\author{
1 Departamento de Nutrição e \\ Saúde (DNS), Universidade \\ Federal de Viçosa (UFV), \\ bolsista CAPES. \\ Endereço eletrônico: \\ glaucedias@yahoo.com.br. \\ 2 Departamento de Nutrição e \\ Saúde (DNS), Universidade \\ Federal de Viçosa (UFV). \\ Endereço eletrônico: \\ rmmitre@ufv.br. \\ ${ }^{3}$ Departamento de Nutrição e \\ Saúde (DNS), Universidade \\ Federal de Viçosa (UFV). \\ ${ }^{4}$ Fundação Educacional da \\ Serra dos Órgãos (FESO); \\ Fundação Osvaldo Cruz \\ (FIOCRUZ). \\ ${ }^{5}$ Fundação Educacional da \\ Serra dos Órgãos (FESO). \\ ${ }^{6}$ Departamento de Nutrição e \\ Saúde (DNS), Universidade \\ Federal de Viçosa (UFV), \\ bolsista CAPES. \\ ${ }^{7}$ Departamento de \\ Enfermagem, Universidade \\ Estadual Paulista (UNESP).
}


A partir da concepção de avaliação, a qual pode ser entendida em suas múltiplas dimensôes de participação, parceria e negociação, como a valoração do sujeito dirigida aos diferentes aspectos de um processo, em um curso marcado por continuidades/disrupções, evidencia-se uma proposta de ponderação que busca superar a hegemonia positivista, assistencialista e curativista. Tal seria uma alternativa à formulação de Reis et al. (2004), para os quais a avaliação pode ser utilizada como instrumento de poder da sociedade moderna para manter hegemonias e maiorias nem sempre justas, sendo associada muito mais a punições que a libertação ou transformação.

Este debate é pertinente ao movimento de implantação de novas estratégias na área da saúde como o Programa Saúde da Família (PSF), criado em 1994 pelo Ministério da Saúde (MS), as quais, apesar de sofrerem fortes influências do modelo assistencial, surgem como possibilidade de emancipação e empoderamento/ libertação do usuário, reformulando seu papel na sociedade como agente promotor de mudanças e de transformações nas práticas de saúde de sua comunidade. "Somos necessariamente éticos, na medida em que constantemente temos que tomar decisões" é uma afirmativa que nos remete não à questão da neutralidade da avaliação, mas ao respeito a todos aqueles que com ela estão envolvidos (FREIRE, 1998; GOMES et al., 2004), colocando indagaçôes sobre os diferentes caminhos a seguir - métodos, do grego meta = atrás, em seguida, através, e hodós = caminho -, tal qual o explicitado por Hartz (2002, p. 5):

Se responder às questões da avaliação não é uma tarefa simples, os programas e políticas de promoção da saúde, com suas ações de natureza emancipadora, participativa, intersetorial e requerendo sustentabilidade de longo prazo, para que possam alcançar o impacto desejado, exigem múltiplas abordagens de pesquisa.

Neste sentido, as inovações propostas pelos novos modelos de avaliação vêm ao encontro desta vanguardista realidade que é o PSF, trazendo consigo uma inovadora perspectiva de atenção, baseada em princípios como integralidade, acolhimento, cuidado a saúde e humanização e que coloca o usuário, a família e a comunidade como o centro de sua atuação. Conseqüentemente, métodos que avaliem a satisfação e a inserção dos usuários - sujeitos envolvidos no processo de produção de saúde e que interagem com outros atores sociais, como profissionais e gestores, e ainda que percebam o contexto, 
que explorem o cotidiano e que retratem sua história - conseguirão gerar respostas, melhorias, construções e desenvolvimento na área da saúde.

Desta forma, este estudo ${ }^{1}$ tem como objetivo analisar, de forma reflexiva, os métodos e modelos de avaliação em saúde, em uma perspectiva do cuidado pensado e praticado segundo as necessidades e demandas do usuário, sujeito social capaz de realizar escolhas.

\section{Marcos conceituais}

Conceituar avaliação é uma tarefa árdua e complexa. De fato, avaliar é um termo possuidor de grande riqueza semântica, sendo aplicável às diversas áreas do saber, além de poder ser considerado um elemento atinente às práticas relativas a diferentes âmbitos e campos do espaço social (SILVA, 2005). Segundo Pires (2005) avaliar, como instrumento do conhecimento, exige delineamento de cotidianos, sendo o processo de avaliação provisório e incompleto. No entanto, é exatamente pela perspectiva de gerar mudanças que a avaliação se apresenta como uma atividade essencial nos programas e políticas de saúde (PAIM, 2005). A avaliação é, por excelência, transformadora - sonhos, metas, ideais e, até mesmo, utopias -, tornando-se explícita sua natureza política (FREIRE, 1998), inscrita em uma lídima matriz dialógica (ROMÃO, 2002).

A avaliação constitui-se numa atividade bastante antiga, processo essencialmente humano e realizado cotidianamente pelo senso comum. Avaliar consiste, no sentido mais geral, em julgar, estimar, medir, classificar, analisar criticamente, enfim, atribuir valor a algo ou a alguém (CONTANDRIOPOULOS et al., 2002; MINAYO et al., 2005; UCHIMIRA; BOSI, 2004).

O conceito de avaliação de programas sociais, que surgiu logo após a Segunda Guerra Mundial como meio para o Estado encontrar formas para a atribuição de recursos (CONTANDRIOPOULOS et al., 2002), é um pouco mais restrito, sendo compreendido como um conjunto de atividades técnico-cientifícas ou técnico-operacionais que buscam atribuir valor de eficiência, eficácia e efetividade a processos de intervenção em sua implantação, implementação e resultados (MINAYO et al., 2005).

Outros autores, influenciados por uma visão positivista na forma de avaliar, enfatizam aspectos objetivos através de dados e validade. Nesta perspectiva, Aguilar e Ander-Egg (1994, p. 23) apresentam a avaliação 
como uma forma de pesquisa social aplicada, sistemática, planejada e dirigida; destinada a identificar, obter e proporcionar de maneira válida e confiável, dados e informação suficiente e relevante para apoiar um juízo sobre o mérito e o valor dos diferentes componentes de um programa [...].

Não obstante, em 1998, a Organização Mundial da Saúde (OMS) acrescenta aspectos relacionados ao ato de avaliar para gerar melhorias e mudanças, conceituando avaliação como um meio sistemático de se aprender empiricamente e de se utilizar as liçôes aprendidas para melhoria das atividades realizadas e para o desenvolvimento de um planejamento mais satisfatório, mediante uma seleção rigorosa entre as distintas possibilidades de ação futura.

Atualmente, análises críticas sobre os diversos tipos de avaliação têm permitido que outras tentativas conceituais e inovadoras apareçam, na busca de superação dos obstáculos operacionais e funcionais para sua execução, e principalmente para que a avaliação gere mudanças e transformações no cotidiano dos serviços de saúde.

Os conceitos até então apresentam o ato de avaliar dentro de um contexto técnico, formalizado, isolado, apoiando o juízo de valor em procedimentos rígidos, numéricos e que gerem respostas ótimas. Mais recentemente, vem-se tornando consenso que a avaliação é sempre algo diferente de uma pura e simples medida científica; o ato de avaliação é um ato de confronto, de correlação, que em grande parte implica "arranjos" e é fruto de negociaçôes (HADJI, 2001). Deste modo, uma definição mais extensa diria que a avaliação é a identificação, o esclarecimento e a aplicação de critérios defensáveis para determinar valor ou mérito a qualidade, eficácia ou importância do objeto avaliado em relação a estes critérios (WORTHEN et al., 2004).

Novos conceitos começam a incorporar aspectos mais subjetivos, como dimensões de participação e parceria, como a definição produzida por Silva \& Brandão (2003), que entendem a avaliação como a elaboração, negociação, como um exercício metodológico cuidadoso e preciso, com vistas a conhecer, medir, determinar e julgar o contexto, o mérito, o valor ou o estado de um determinado objeto, a fim de estimular processos de aprendizagem e do desenvolvimento das pessoas e das organizações. Esses autores ressaltam, ainda, as questões estratégicas no ato de avaliar, as quais incluem a perspectiva de mudar, emancipar, transformar. Retratam, igualmente, aspectos que exigem parceria como negociação, elaboração não como um evento isolado, mas que gerem mudanças facilitando o processo de aprendizagem e do desenvolvimento de pessoas e organizações. Uma avaliação que inclua os diferentes 
sujeitos sociais é o caminho pelo qual homens e mulheres podem se tornar conscientes de sua presença no mundo. A maneira como atuam e pensam quando participam efetivamente do processo de avaliação, tomando em consideração suas necessidades e aspirações dos outros (FREIRE; FREI BETTO, 1985).

Desta forma, é necessário uma concepção que leve em consideração os valores, as preocupações e percepções dos interessados em relação ao objeto da avaliação, sendo que a partir desta abordagem a avaliação deva atingir um clímax de responsabilidade e participação. Desde esta perspectiva, na medida em que avaliados e avaliadores dialoguem, instituições e sistemas se sintonizem, a avaliação irá emergindo com suas características propulsoras das necessárias transformações educacionais e sociais e na defesa dos direitos humanos (PENNA, 2003). Há um fundamento ético da presença de cada homem no mundo. Para isso, necessita-se de liberdade aliada à capacidade de assumir riscos, decidir, romper, arriscar a liberdade, independência e empoderamento/libertação, que neste caso andam juntos (FREIRE, 1998).

\section{Métodos de avaliação em saúde}

Os métodos de avaliação são essenciais para verificação daquilo que se quer com o processo avaliativo, ou seja, para cada objeto de avaliação um método será mais adequado que outro na busca do conhecimento desejado; diferentes métodos para diferentes objetos de avaliação (HARTZ, 2002; HARTZ; CONTANDRIOPOULOS, 2004).

No caso da saúde, são apresentados métodos que buscam alternativas que cada vez mais considerem os sujeitos e a dinâmica da realidade como fatores inerentes ao cenário/foco da verificação, em que pese ainda continuem cercados de características hegemônicas como caráter estrutural-funcionalista, positivista e autoritarista (PIRES, 2005).

No Brasil, há uma tendência histórica na administração pública de privilegiar dados quantitativos, caracterizados pelo uso de pressupostos típicos do modelo positivista (LOBO, 1998). Concordando com Houaiss (2001), este é um sistema criado por Auguste Comte (1798-1857) e desenvolvido por inúmeros epígonos, que se propõe a ordenar as ciências experimentais, considerando-as o modelo por excelência do conhecimento humano, em detrimento das especulações metafísicas ou teológicas; filosofia positiva, comtismo. 
Por extensão, tem-se positivismo como "cada uma das doutrinas influenciadas pelo comtismo nos séculos XIX e XX, caracterizadas pelo cientificismo, metodologia quantitativa e hostilidade ao idealismo". Conseqüentemente, o hábito positivista de pesquisar amarrado ao dado e a sua relação fundamentalmente quantitativa com outra informação, priva o novo enfoque da possibilidade de interpretações ricas das realidades estudadas (TRIVINÕS, 1987).

Segundo Richardson (1999, p. 70):

o método quantitativo de avaliar é caracterizado pelo emprego da quantificação tanto das modalidades de coletas de informaçôes, quanto no tratamento delas por meio de técnicas estatísticas e possui a intenção de garantir a precisão dos resultados, classificando a relação entre as variáveis, bem como nos que investigam a relação de causalidade entre fenômenos.

Já o método qualitativo

caracteriza-se com a tentativa de uma compreensão detalhada dos significados e características situacionais apresentadas pelos entrevistados, em lugar da produção de medidas quantitativas de características ou comportamentos. (RICHARDSON, 1999, p. 70).

No entanto, vale ressaltar que esta diferença conceitual e estabelecida na prática, de um lado, deixa à margem dados que não podem ser contidos em números e de outros aspectos contemplando somente significados subjetivos omitindo uma realidade estruturada (MINAYO, 1996). Gurvitch et al. (1945) apud Minayo (1996) advertem que estas duas dimensões da avaliação (quantitativa e qualitativa) são interdependentes e interagem não podendo ser pensadas de formas dicotômicas. Entretanto, é preciso ficar claro que o uso de um ou outro método implica definir claramente o que se quer saber ou explicar, especialmente na área da saúde, na qual uma visão apenas positivista não irá responder à dialética atuação do processo saúde-doença na sociedade.

As novas tendências têm revelado que mais importante que discutir qual o melhor método para responder aos questionamentos ou problemas apresentados é ter claro o que é importante saber e de fato utilizar a informação produzida por tal método. Nesta perspectiva, é crucial descobrir o que é preciso fazer para criar e desenvolver avaliações que sejam realmente utilizadas para reduzir incertezas, melhorar a efetividade e direcionar decisões relevantes, uma vez que, de fato, seu significado maior está em fortalecer o movimento que leva à transformação (LOBO, 1998). 
Ainda segundo Penna (2003), a preocupação central dos estudiosos é estabelecer padrões de excelência para a avaliação, gerando um conjunto de critérios agrupados em quatro categorias: (1) utilidade; (2) viabilidade; (3) ética e (4) precisão da avaliação, sendo que tais critérios clamam por análises mais sensíveis à situação local, sendo metodologicamente flexíveis e dinâmicas no entendimento político integrando tais categorias na direção do desenvolvimento e aperfeiçoamento do objeto.

Agrupando tais critérios, ou não, utilizando métodos qualitativos ou quantitativos ou ambos, várias estratégias são utilizadas para melhor explicar seu objeto de estudo ou solucionar e explicar os problemas e resultados de determinada instituição, empresa, programa ou conjunto de indivíduos.

\section{Desenhos, paradigmas e formas de avaliação}

Os atributos referem-se às características das práticas de saúde e da sua organização social, contribuindo para o aprofundamento no processo de definição do foco da avaliação. Podem ser agrupados em (1) relacionados à disponibilidade e distribuição social dos recursos (cobertura, acessibilidade e equidade); (2) que dizem respeito aos efeitos das ações e práticas de saúde (eficácia, efetividade e impacto); (3) pautadas nos custos das açôes (eficiência); (4) pertinentes à adequação das ações ao conhecimento técnico e científico vigente (qualidade técnico-científica); (5) relacionados à percepção dos usuários sobre as práticas (satisfação dos usuários, aceitabilidade) (SILVA; FORMIGLI, 1994). A utilização destas noções varia muito de autor para autor (DONABEDIAN, 1990; VUORI, 1982). No entanto, caracterizar alguns atributos e verificar de que forma entram no contexto da avaliação é tarefa importante e desejável.

Acessibilidade tem sido definida como uma relação entre os recursos de poder dos usuários e os obstáculos colocados pelos serviços de saúde. Os recursos de poder podem ser de natureza econômica, social e cultural. Já os obstáculos podem ser geográficos (distância, transporte), organizacionais (existência de filas, tempo de espera, natureza do acolhimento), econômicos (SILVA, 2005) e culturais. Nesse sentido, é importante consideramos que o conceito de acesso, tal qual trabalhado por Penchansky \& Thomas (1981), que lista como uma das dimensões do acesso o acolhimento (accomodation), visto como representando a relação entre a forma como os serviços se organizam para receber os clientes e a capacidade dos clientes para se adaptar a essa organização. 
A segunda e importante característica das práticas de saúde diz respeito aos efeitos sobre o estado de saúde dos indivíduos, grupos ou populações. A distinção sobre eficácia e eficiência, duas abordagens relacionadas aos efeitos, é discutida por Fekete (2000), autor que caracteriza a primeira como uma medida normativa do alcance dos resultados, referida à capacidade de contemplar as necessidades da sociedade pelo suprimento de produtos, visando ao alcance dos objetivos propostos; e a segunda como aquela capaz de mensurar a utilização dos recursos, estando voltada para a aplicação dos métodos, a fim de que os recursos (físicos, materiais e humanos) sejam aplicados de forma mais racional, relacionando-se, portanto, com os meios e não com os fins.

Com o objetivo de avaliar os meios proporcionados por determinadas práticas de saúde para verificação dos efeitos a saúde, a qualidade técnico-científica do cuidado seria um atributo no sentido que lhe foi dado por Vuori (1982), correspondente à adequação das ações ao conhecimento técnico e científico vigente, ou seja, seria verificar em que medidas as tecnologias estão sendo usadas, considerando serem as mais indicadas à população.

Por fim, os atributos "relacionais" criam uma nova perspectiva para a avaliação em saúde. Correspondem a valorizar as características do acolhimento, a garantia dos direitos individuais à privacidade e as características das relações no trabalho, assim como a satisfação dos usuários como componente da qualidade da atenção (SILVA, 2005; MERHY, 2002).

A qualidade da atenção em saúde é vista por alguns autores, como Donabedian (1984), como o aspecto central a ser considerado na avaliação em saúde. O esforço mais bem-sucedido de classificação das abordagens para a avaliação em saúde foi desenvolvido por ele - no âmago de uma concepção pautada na tríade "estruturaprocesso-resultado" -, a partir do referencial teórico sistêmico. Para esse autor, a estrutura corresponderia às características relativamente estáveis de seus provedores, aos instrumentos e recursos, bem como às condiçôes físicas e organizacionais; o processo corresponderia ao conjunto de atividades desenvolvidas na relação entre profissionais e usuários; e os resultados seriam as mudanças verificadas no estado de saúde dos pacientes que pudessem ser atribuídas a um cuidado prévio (DONABEDIAN, 1984). Podem ser considerados como resultados, mudanças relacionadas com conhecimentos e comportamentos, bem como a satisfação do usuário decorrente do cuidado sanitário prestado (VUORI, 1982). 
Contandriopoulos et al. (2002) assumem a existência de duas formas de proceder à avaliação, ao julgamento de valor: a partir do resultado da aplicação de critérios e normas (avaliação normativa) ou a partir de um procedimento científico (pesquisa avaliativa). A avaliação normativa é definida como atividade capaz de realizar um julgamento, comparando recursos estruturais e organizacionais com bens produzidos e os resultados obtidos com critérios e normas; já a pesquisa avaliativa, com procedimentos que utilizam métodos científicos.

Ainda de acordo com Contandriopoulos et al. (2002), a pesquisa avaliativa se decompõe em seis tipos de análise: (1) análise estratégica: trata-se de analisar a pertinência da intervenção, isto é, analisar a adequação estratégica entre a intervenção e a situação problemática que deu origem à intervenção; (2) a análise de intervenção, que consiste em estudar a relação que existe entre os objetivos de intervenção e os meios empregados; (3) a análise de produtividade, que consiste em estudar o modo como os recursos são usados para produzir serviços; (4) análise dos efeitos, que se baseia em avaliar a influência dos serviços sobre os estados de saúde; (5) análise do rendimento ou da eficiência, que consiste em relacionar a análise dos recursos empregados com os efeitos obtidos; (6) análise da implantação, que consiste em mediar a influência que pode ter a variação no grau de implantação de uma intervenção nos seus efeitos e, por outro, apreciar a influência do ambiente, no contexto, no qual a intervenção está implantada.

Todavia, devem-se destacar as abordagens do método qualitativo, como por exemplo, as representações sociais e o estudo de caso. Ao se investigar as diferentes representações da doença ou de determinado tratamento, os serviços podem ser considerados espaços onde tais representaçôes se reproduzem ou se reatualizam. Essas representaçōes não surgem do vazio; elas são construídas historicamente, no campo das interações, sofrendo influência das estruturas cristalizadas, orientando e sendo orientadas pela ação dos sujeitos em suas práticas cotidianas (DESLANDES; GOMES, 2004).

Segundo Becker (apud DESLANDES; GOMES, 2004), o estudo de caso em ciências sociais possui duplo objetivo. O primeiro deles se volta para a tentativa de compreender, da forma mais abrangente possível, o grupo ou a organização de estudo, e o segundo objetivo diz respeito à tentativa de desenvolver declarações teóricas mais gerais sobre regularidades do processo e estruturas sociais. 
Diante das diferentes e distintas abordagens e formas de avaliar, verificamos que inovações recentes no ato de avaliar evidenciam estratégias como avaliação participativa e investigação avaliativa por triangulação de métodos. Nesta, a autoavaliação faz parte do processo, mas o conjunto de elementos e procedimentos é muito mais amplo e complexo do que a avaliação participativa, por conjugar métodos quantitativos e qualitativos, análise do contexto, da história, das relações, das representações e a participação (MINAYO et al., 2005).

Percebe-se que diante das diferentes formas de avaliação em saúde proposta por diferentes autores, a inserção do usuário no processo avaliativo tem sido muito valorizada. Incluir o usuário como agente de transformação e avaliação apresenta-se como um indicador sensível de qualidade do serviço, ligado a uma maior adequação e promoção de reais mudanças nos serviços de saúde (ESPERIDIÃO; TRAD, 2006).

\section{A satisfação do usuário em pauta}

As primeiras pesquisas no campo da avaliação em saúde, ainda na década de 1970, referiam-se à satisfação do usuário (VAITSMAN; ANDRADE, 2005). O objetivo era conseguir melhores resultados clínicos, a partir do comparecimento às consultas, aceitação das recomendações e prescrições e uso adequado dos medicamentos - ou seja, adesão ao tratamento. Anteriormente, as pesquisas na área das Ciências Sociais e Humanas (COSER, 1962; CARTWRIGHT, 1964) focalizavam relaçôes médico-paciente, no contexto da clínica ou do ambiente hospitalar. No Brasil, os estudos se desenvolveram na década de 90, a partir do fortalecimento do controle social do Sistema Único de Saúde (SUS), por intermédio da participação da comunidade nos processos e questões relferentes ao planejamento e avaliação (ESPERIDIÃO; TRAD, 2006).

Em 1984, com Donabedian, a noção de satisfação do paciente tornou-se um dos elementos-chave na avaliação da qualidade em saúde, ao lado da avaliação do médico e da comunidade. A partir de então, os usuários não puderam ser ignorados, e a idéia de satisfação do paciente tornou-se um objetivo em si e não apenas um meio de produzir a adesão ao tratamento, como era comum nos objetivos dos estudos anteriores (VAITSMAN; ANDRADE, 2005).

De acordo com Valdés-Salgado et al (2001), as avaliações baseadas na satisfação dos usuários permitem desenhar diferentes estratégias alternativas aos serviços, a partir do entendimento de saúde física e mental produzida pela sociedade e 
influenciada pelas formas de organização de vida cotidiana, sociabilidade, efetividade, subjetividade, cultura e lazer, das relaçóes com o meio ambiente, resultante do conjunto da experiência social individualizada em cada sentir e vivenciada num corpo que é também, não esqueçamos, biológico (CARVALHO, 2005). Neste sentido, valorização da qualidade dos serviços a partir das perspectivas dos usuários possui papel fundamental para explicar a satisfação ou insatisfação reportada, em que a atualização do pensamento sanitário contemporâneo está a exigir a compreensão dos indivíduos na sua complexidade de sujeitos sociais lidando com os resultados de suas escolhas e de sua intervenção (CARVALHO, 1996).

A partir desta perspectiva de qualidade, muitas são as variáveis que produzem a satisfação. A pesquisa de Weiss (1988) sobre os fatores e determinantes da satisfação tem sido bastante citada, e apresenta quatro grupos principais: (1) características do paciente; expectativas destes sobre a consulta médica e seu estado de saúde; (2) aspectos dos profissionais que prestam o atendimento; (3) características da relação profissional de saúde-paciente; (4) fatores estruturais e ambientais. De acordo com este autor, as expectativas sobre a consulta médica e os desejos do paciente devem ser mais exploradas pelos médicos, pois os usuários têm dificuldade de os expressar verbalmente e, ao não terem respostas, estes sentimentos podem se transformar em fator de tensão e frustração. Com relação às características dos profissionais e aspectos da relação médico-paciente, Weiss (1988) considera que a atitude passiva do paciente frente ao saber médico e a dificuldade de expressar verbalmente suas dúvidas e inquietações somam-se à natureza da moderna tecnologia médica, dificultando ao médico avaliar a satisfação do usuário no transcorrer de uma consulta.

Ramiréz-Sanchez et al. (1998) apontam, em sua pesquisa realizada no México, a estratégia de Donabedian. Analisam a qualidade das três dimensões que propõe o autor: estrutura, processo e resultado. Utilizam a satisfação como indicador de qualidade, a partir do qual obteviveram opiniāo sobre os aspectos de estrutura (comodidades e instalações físicas, organização), processo (procedimentos e açōes realizadas na consulta) e resultado (mudanças do estado de saúde e percepção geral da atenção recebida), obtendo ainda informações sobre características dos serviços que facilitam ou obstaculizam os esforços do usuário para obter atenção.

Outros estudos estruturam-se a partir de técnicas qualitativas, como o grupo focal, para avaliar a satisfação e percepções dos usuários, que se caracteriza pela 
discussão de um grupo relativamente homogêneo de temas propostos pela avaliação. O grupo é guiado por um facilitador e a discussão gravada. É uma técnica que tem sido valorizada por constituir-se na coleta de informaçóes de caráter qualitativo em profundidade, em curto espaço de tempo e baixo custo (MINAYO, 1996).

Trad et al. (2002) utilizam o grupo focal com conteúdos propostos por Prevost et al. (1998), com base nas seguintes dimensões: necessidade (carências referidas, demandas associadas com saúde); cognitiva (percepção sobre o programa, idéia central); relacional: (respeito e consideração, escuta, compreensão, acolhida, gentileza por parte dos profissionais da equipe); organizacional: tempo de espera (por horário disponível e já no local de atendimento), horário de abertura e funcionamento, horário dos profissionais, localização dos serviços, acesso à informação; profissional: tempo dispensado, informações suficientes e claras, implicação da busca de soluçôes, qualidade ou competência, eficácia dos serviços, disponibilidade.

Diante dos estudos presentes na literatura, podem-se identificar dois grandes grupos relacionados à satisfação, um relativo ao serviço e seus provedores, e outro inerente aos seus próprios usuários. Apesar da divergência no que se refere às dimensões relativas ao usuário, destaca-se a variável gênero - embora alguns estudos não encontrem variação, outros apontam que as mulheres estão mais aptas a criticar os serviços, constituindo boas informantes para a pesquisa (VALDÉS-SALGADO et al. 2001; COYLE, 1999). Já o fator renda e escolaridade, embora a literatura internacional não informe a existência de associação com a satisfação, parece haver no Brasil uma correlação inversa, os usuários de camadas mais populares informam estar mais satisfeitos (LEMME et al., 1991; SANTOS, 1995).

Em relação aos determinantes relativos aos serviços de saúde, a maioria dos estudos atribui a satisfação a aspectos humanitários da relação médico-paciente, a quantidade e qualidade das informações recebidas, à efetividade dos problemas e continuidade do atendimento (QUEIROZ et al., 1992; RAMADAM, 2004). No caso do Brasil, além dos fatores humanitários, a literatura referencia a satisfação dos usuários ao acesso aos serviços e disponibilidade de insumos, como vacinas e medicamentos (ESPERIDIÃO; TRAD, 2006; SANTOS, 1995).

Alguns autores têm buscado compreender o fenômeno da alta satisfação. No caso dos serviços públicos, argumenta-se que a alta satisfação expressa o receio dos usuários em perder o direito ao serviço, mesmo sendo este de baixa qualidade (GOMES et al., 1999). Ademais, o viés da gratidão costuma ser encontrado nos 
países em desenvolvimento, referindo-se a omissão de questionamentos e críticas negativas dos usuários (ESPERIDIĀO; TRAD, 2006; COTTA et al., 1998).

Yépez \& Morais (2004) enfatizam que há uma certa "naturalização" para baixa qualidade na visão de alguns usuários - os quais terminam por reconhecer o serviço recebido como um favor ou doação e não como um direito -, o que representa uma das diferentes interpretações para o gratuito. Flores et al. (2000) verificaram que a população atendida pelos serviços de saúde odontológicos não tem expectativas altas com relação aos atendimentos e que é a única possibilidade de acesso à população de baixa renda.

A fim de trabalhar melhor os vieses apontados, alguns autores destacam a importância de se comparar as respostas abertas e fechadas do questionário, pois é comum o usuário atribuir uma alta avaliação nas respostas fechadas e nas abertas incluir restriçôes e recomendaçôes sobre o mesmo item, daí a importância de se conjugar métodos qualitativos e quantitativos (KOTAKA et al., 1997). Williams (1994) considera que antes de se avaliar a satisfação do usuário é necessário perceber quais os mecanismos que o mesmo utiliza para avaliar o serviço em questão, ou seja, entender o processo cognitivo, buscando no ideário do usuário o significado do termo satisfação.

Apesar das limitações apresentadas, a incorporação do usuário na avaliação e sua satisfação constituem indicadores sensíveis da qualidade do serviço prestado, além de estar potencialmente ligado à maior adequação do serviço (TRAD et al., 2001). O que é importante observar são as técnicas utilizadas e como são empregadas. De acordo com Espiridião \& Trad (2005, p. 305) "uma combinação de técnicas é uma estratégia bastante oportuna para dar conta da complexidade da satisfação e evitar reducionismos presentes em cada método". Este desafio enseja, ao mesmo tempo, uma releitura do lugar do usuário no contexto de produção social em saúde que deve apontar para uma perspectiva não-reducionista que recupere o significado deste, em sua subjetividade, na relação com os outros atores sociais ligados aos serviços de saúde e com o mundo (CARVALHO, 2005), dentro dos contemporâneos referenciais da complexidade (CASTRO, 2002; TARRIDE, 1998). 
Avaliação em saúde e Programa Saúde da Família

As inovações propostas pelos novos modelos de avaliação vêm ao encontro de uma nova realidade presente nos serviços de saúde brasileiros, que é o PSF. Trazem consigo uma nova perspectiva de atenção, baseada em princípios como acolhimento, cuidado e humanização e que coloca o usuário, a família e a comunidade como o centro de sua atuação.

A idéia de humanização passa a ser compreendida como "a valorização dos diferentes sujeitos implicados no processo de produção de saúde” (BRASIL, 2004), concebendo um valor positivo à alocação do sujeito implicado na produção da saúde, designando o usuário como principal, quando não único, alvo da humanização (REIS et al., 2004).

Já a proposta de cuidado à saúde expressa por Ayres (2004) nos remete não só a práticas e procedimentos de saúde, mas também a um construto teórico, caracterizando-a como atitude prática e compreensão filosófica frente ao sentido que as ações de saúde adquirem nas diversas situações em que se exige uma ação terapêutica. Isto é, uma interação entre dois ou mais sujeitos visando ao alívio de um sofrimento ou ao alcance de um bem-estar, mediada por saberes especificamente voltados para essa finalidade.

O acolhimento, como mostram diversos autores (SILVA JÚNIOR et al., 2003; TEIXEIRA, 2003), é um recurso fundamental para que o outro do cuidador surja positivamente no espaço assistencial, tornando suas demandas efetivas como o norte das intervenções propostas em seus meios e finalidades. Esses autores também destacam que o acolhimento não pode ser confundido com recepção, ou mesmo com pronto-atendimento, como se chega a considerá-lo em situação descrita por Teixeira (2003). É no contínuo da interação entre usuários e serviços de saúde, em todas as oportunidades em que se faça presente a possibilidade de escuta do outro, que se dá o acolhimento, o qual deve ter entre suas qualidades essa capacidade de escuta (AYRES, 2004).

Diante de tais afirmações, verifica-se a profunda inserção da população nos princípios que fundamentam o PSF, ressaltando a participação e satisfação da comunidade como um elemento-chave do processo avaliativo, permitindo que o usuário participe nos rumos que a unidade de saúde deve seguir. Pensar a saúde hoje passa então por pensar o indivíduo em sua organização da vida cotidiana, tal como esta se expressa não só através do trabalho, mas também do lazer - ou 
da sua ausência - por exemplo, do afeto, da sexualidade, das relações com o meio ambiente. Uma concepção ampliada de saúde passaria então por pensar a recriação da vida sobre novas bases (CARVALHO, 2005). É sobre esses pilares que se deve construir o cotidiano das ações e serviços do PSF.

Abordagens qualitativas cumprem aqui um papel importante, visto a verificação de aspectos como acolhimento, cuidado e humanização que não podem ser quantificados numericamente e retratados unicamente a partir de dados, mas implica uma subjetividade interligada ao contexto histórico, a realidade e experiências vividas pelos usuários, profissionais e gestores (PIRES, 2005). Por outro lado, abordagens quantitativas podem estruturar melhor a realidade estudada e auxiliar o processo avaliativo. Portanto, os dois modelos poderão ser utilizados concomitantemente, um apoiando o outro na busca de respostas e mudanças geradas pela avaliação.

O importante neste processo de avaliação em saúde é cada vez mais a necessidade de inserir a comunidade no processo avaliativo, interagindo com outros atores sociais na busca de melhorias e transformações das práticas de saúde locais. É claro que existem vários desafios para o surgimento de uma avaliação mais participativa na área da saúde, justamente porque existe o discurso imperativo e que dá ênfase e promove a relação curativa e assistencial, que estima como menores as ações preventivas e suprime, na consideração diagnóstica, os fatores que possam suprimir do estatuto socioeconômico ou subjetivo, singular, do usuário atendido (REIS et al., 2004). Este modelo assistencial continua a influenciar as estratégias de avaliação, fazendo com que estas sejam produzidas como eventos isolados e superficiais - ou seja, incapazes de dar conta da realidade -, mantendo desta forma sua carcomida hegemonia.

A lógica deste "velho" modelo revela práticas que aparecem como elementos institucionais produtores de sujeitos fragmentados, burocratizados na sua relação com os usuários, individualistas e distantes da percepção da sua própria importância na sustentação da política de saúde, na qual se acham imersos, gerando apatia e indiferença (REIS et al., 2004). Tais práticas devem considerar e valorizar a subjetividade do usuário não apenas por uma questões ética, mas também por entender que o envolvimento e a participação dos usuários só são possíveis mediante um processo de diálogo entre saberes, no qual cada um contribui com seu conhecimento peculiar da situação, acreditando que o desenvolvimento efetivo parte de práticas vivenciadas no cotidiano (YÉPEZ; MORAIS, 2004). 
A política de humanização amplia o espaço para métodos avaliativos de participação e interação do sujeito, uma vez que surge como um instrumento que reverte um poder centralizado, que envolve naturalmente risco e responsabilidade, para um poder compartilhado, no qual diferentes atores sociais profissionais, usuário e gestores, possam sustentar e transformar o delicado processo de prevenção e promoção da saúde.

O PSF, mesmo que na prática e em alguns momentos seja ainda influenciado pelo modelo assistencial hegemônico, possui dimensôes, em sua tessitura ideológica, que podem superar tal modelo, integrando propostas participativas e interativas que potencializam mudanças, transformações e emancipação.

\section{Considerações finais}

A avaliação em saúde, como proposta indutora de mudanças, deve apostar em um método que priorize a participação e a inserção do usuário nas atividades inerentes ao próprio processo, considerando-o não como um evento isolado, mas sim interativo, promocional e emancipador/libertador.

Para isso, devem ser superadas propostas isoladas, incapazes de perceber a realidade - especialmente o contexto e os seus múltiplos significados -, de cada região, desconsiderando seus sujeitos. É necessário não só gerar informações, mas utilizá-las, transformá-las, dissecá-las para a produção de melhoria das condiçôes de vida - incluída a saúde - de uma população. Deste modo, a avaliação da satisfação do usuário destaca-se, de fato, como um instrumento potencializador nos estudos das relações interpessoais no âmbito dos serviços de saúde e como instrumento de controle social.

A partir do desenho inovador do PSF - o qual possui seus princípios respaldados no cuidado à saúde, no acolhimento e humanização e na integralidade -, é necessário o reconhecimento do usuário como cidadão, do doente como pessoa, promovendo, ato contínuo, a inserção do usuário como um agente importante na construção da sua própria saúde. 


\section{Referências}

AGUILAR, M. J.; ANDER-EGG, E. Avaliação de serviços eprogramas sociais. Petrópolis: Vozes, 1994. AYRES, J. R. C. M. Cuidado e reconstrução das práticas de saúde. Interface-Comunicação, Saúde, Educação, v. 8, n. 14, p. 73-92, 2004.

BRASIL. Ministério da Saúde. Política Nacional de Humanização: documento base para gestores e trabalhadores do SUS. Brasília: Ministério da Saúde, 2004. 54 p.

CARTWRIGHT A. Human relations and hospital care. Reports of Institute of Community Studies, v. 9, p. 251-254, 1964.

CARVALHO, S. R. Saúde Coletiva e promoção da saúde: sujeito e mudanças. São Paulo: Hucitec, 2005.

CARVALHO, A. I. Da saúde pública às políticas saudáveis: saúde e cidadania na pós-modernidade. Ciência e Saúde Coletiva, Rio de Janeiro, v. 1, p. 104-121, 1996.

CASTRO G. Ensaios de complexidade. Porto Alegre: Sulina, 2002.

CONTANDRIOPOULOS, A-P. et al. A avaliação na área da saúde: conceitos e métodos. In: HARTZ, Zulmira A. M. (Org.). Avaliação em saúde: dos modelos conceituais à prática na implantação de programas. 3. ed. Rio de Janeiro: Fiocruz, 2002. p. 29-46.

COSER, L. A. Some functions of deviant behavior and normative flexibilit. American Jornal of Sociology, v. 68, n. 2, p. 172-181, 1962.

COTTA, R. M. M.; MENDES, F. F.; MUNIZ, J. N. Descentralização das políticas públicas de saúde: do imaginário ao real. Viçosa: UFV, 1998. 148p.

COYLE, J. Exploring the meaning of dissatisfaction with health care: the importance of personal identity threat. Sociol Health Illn, v. 21, p. 95-123, 1999.

DESLANDES, S. F.; GOMES, R. A pesquisa qualitativa nos serviços de saúde: notas teóricas. In: BOSI, M. L. M.; MERCADO, F. J. Pesquisa qualitativa de serviços de saúde. Petrópolis: Vozes, 2004. p. 99-120.

DONABEDIAN, A. The seven pilars of quality. Archives of Pathology Laboratory Medicine. v. 114, p. $1.115-1.118,1990$.

DONABEDIAN, A. La calidad de la atención médica: definición y métodos de evaluación. México, DF: La Prensa Mexicana, 1984.

ESPERIDIÃO, M. A.; TRAD, L. A. B. Avaliação de satisfação de usuários. Ciência \& Saúde coletiva, Rio de Janeiro v. 10, p. 303-312, 2005.

ESPERIDIÃO, M. A.; TRAD, L. A. B. Avaliação de satisfação de usuários: considerações teóricoconceituais. Cadernos de Saúde Pública, Rio de Janeiro, v. 22, p. 1.267-76, 2006. 
FEKETE, M. C. A qualidade na prestação do cuidado. In: OPAS. Representação do Brasil; Pólo de Capacitação da UFMG. Organização do cuidado a partir de problemas. p. 51-57, 2000. Disponível em: <htpp/www.opas.org.br/rh/publicações/texto_apoio>. Acesso em: jul. 2006.

FLORES, N. L. et al. Satisfacción de usuarios de dos servicios odontológicos en Tlahuac, Distrito Federal. Revista ADM., n. LVII, p. p. 45-49, 2000.

FREIRE, P. Pedagogy offreedom: ethics, democracy and civic courage. Maryland: Rowman and Littlefield, 1998.

FREIRE, P.; FREI BETTO. Essa escola chamada vida. São Paulo: Ática, 1985.

GOMES, A. P. et al. A formação médica: revisitando Paulo Freire. Revista Digital de Educação Permanente em Saúde, v. 1, p. 236, 2004.

GOMES, R. et al. Avaliação da assistência ambulatorial a portadores do HIV-Aids no Rio de Janeiro, segundo a visão dos usuários. Cadernos de Saúde Pública, Rio de Janeiro, v. 15, p. 789-97, 1999.

HADJI, C. Avaliação desmistificada. Porto Alegre: Artmed, 2001.

HARTZ, Z. M. A.; CONTANDRIOPOULOS, A-P. Integralidade da atenção e integração de serviços de saúde: desafios para avaliar a implantação de um "sistema sem muros". Cadernos Saúde Pública, v. 20, n. 2, p. S331-S336, 2004.

HARTZ, Z. M. A. Novos desafios para a Avaliação em Saúde: lições preliminares dos Programas de Promoção. Rev. Bras. Saúde Matern. Infant., Recife, v. 2, n. 1, p. 5-6, 2002.

HOUAISS, Antonio. Dicionário eletrônico Houaiss da língua portuguesa. Rio de Janeiro - Editora Objetiva, 2001 [CD]

KOTAKA, F.; PACHECO, M. L. R.; HIGAKI, Y. Avaliação pelos usuários dos hospitais participantes do programa de qualidade hospitalar no Estado de São Paulo, Brasil. Revista de Saúde Pública, São Paulo, v. 31, n. 2, p. 171-177, 1997.

LEMME, A. C.; NORONHA, G.; RESENDE, J. B. User satisfaction at a university hospital. Rev. Saúde Pública, São Paulo, v. 25, n. 1, p. 41-46, 1991.

LOBO, T. Avaliação de processos e impactos em programas sociais: algumas questôes para reflexão. In: RICO, E. M. (Org.). Avaliação de Políticas Sociais. São Paulo: Cortez, 1998. p. 75-84.

MERHY, E. M. Introdução ao debate sobre os componentes da caixa de ferramentas dos gestores em saúde. Ver SUS/Brasil - Vivências e estágios na realidade do SUS do Brasil, 2002. Disponível em: <http://dtr2002.saude.gov.br/versus/index.html> Acesso em: 28 jan. 2006.

MINAYO, M. C. S.; ASSIS, S. G.; SOUZA, E. R. Avaliação por triangulação de métodos: abordagem de programas sociais. Rio de Janeiro: Fiocruz, 2005.

MINAYO, M. C. O desafio do conhecimento: pesquisa qualitativa em saúde. São Paulo: Hucitec, 1996. 265p. 
ORGANIZACIÓN MUNDIAL DE LA SALUD. Organización Panamericana de Salud)

Evaluación de Servicios de la Salud Materno-Infantil. Castalleda, Venezuela, 1998.

PAIM, J. S. Avaliação em saúde: uma prática em construção no Brasil. In: HARTZ, Z. M. A.; SILVA, L. M. V. Avaliação em saúde. Rio de Janeiro: Fiocruz, 2005. p. 15-39.

PENCHANSKY, D. B. A.; THOMAS, J. W. The concept of access: definition and relationship to consumer satisfaction. Med Care, n. 19, p. 127-40, 1981.

PENNA, F. T. Avaliação em rede. 2003. Disponível em: http://www.rits.org.br/redes_teste/ rd_tmes_set2003.cfm. Acesso em: 05 mai. 2006.

PIRES, M. R. G. M. Politicidade do cuidado e avaliação em saúde: instrumentalizando o resgate da autonomia de sujeitos no âmbito de programas e políticas de saúde. Revista Brasileira de Saúde Materno-Infantil. Recife, v. 5, n. 1, p. 571-581, 2005.

PRÉVOST, A.; FAFARD, A.; NADEAU, M. A. La mesure de la satisfaction des usagers dans le domaine de la santé et des services sociaux: l'experience de la Régie Régionale Chadière-Appalaches. The Canadian Journal of Program Evaluation, v. 13, n. 1, p. 1-23, 1998.

QUEIROZ, M. S.; CAMPOS, G. W. S.; MERHY, E. E. Rede básica de serviços de saúde: médicos e suas representações sobre o serviço. Rev. Saúde Pública, São Paulo, v. 26, n. 1, p. 34-40, 1992.

RAMADAM, Z. B. A. O médico e o paciente: breve história de uma relação delicada. Rev.Psiquiatria Clínica, São Paulo, v. 31, n. 2, p. 108-118, 2004.

RAMÍREZ-SANCHÉZ, T. J. R.; AGUILAR, N. P.; LÓPEZ, N. G. Percepción de la calidad de la atención de los servicios de salud en México: perspectiva de los usuarios. Revista de salud pública de México, v. 40 n.1, p. 1-10, 1998.

REIS, A. O.; MARAZINA, I. V.; GALO, P. R. A humanização na saúde como instância libertadora. Saúde e Sociedade, São Paulo, v. 13, n. 3, p. 36-43, 2004.

RICHARDSON, R. J. et al. Pesquisa social: métodos e técnicas. São Paulo: Atlas, 1999. 334p.

ROMÃO, J. E. Avaliação dialógica: desafios e perspectivas. São Paulo: Cortez, 2002.

SANTOS, M. P. Avaliação da qualidade dos serviços públicos de atenção à saúde da criança sob a ótica do usuário. 1995. Dissertação (Mestrado em Saúde Coletiva) - Instituto de Saúde Coletiva, Universidade Federal da Bahia, Salvador, 1995.

SILVA, L. M. V. Avaliação em saúde. Rio de Janeiro: Fiocruz, 2005.

SILVA JÚNIOR, A. G.; MERHY, E. E.; CARVALHO, L. C. Refletindo sobre o ato de cuidar da saúde. In: PINHEIRO, R.; MATTOS, R. A. (Orgs.). Construção da integralidade: cotidiano, saberes e práticas em saúde. Rio de Janeiro: Abrasco, 2003. p. 113-128.

SILVA, R. S.; BRANDÃO D. Construção da capacidade avaliativa em organizações da sociedade civil. São Paulo: Instituto Fontes, 2003. 
SILVA, L. M. V.; FORMIGLI, V. L. Avaliação em saúde: limites e perspectivas. Cad. de Saúde Pública, v. 10, p. 80-91, 1994.

TARRIDE, M. I. Saúde pública: uma complexidade anunciada. Rio de Janeiro: Fiocruz, 1998.

TEIXEIRA, R. R. Acolhimento num serviço de saúde entendido como uma rede de conversaçóes. In: PINHEIRO, R.; MATTOS, R. A. (Orgs.). Construção da integralidade: cotidiano, saberes e práticas em saúde. Rio de Janeiro: Abrasco, 2003. p. 49-61.

TRAD, L. A. B. et al. Estudo etnográfico da satisfação do usuário do Programa de Saúde da Família (PSF) na Bahia. Ciência e Saúde Coletiva. Rio de Janeiro, v. 7, p. 581-89, 2002.

TRAD, L. A. B. et al. A construção social da estratégia de saúde da família: condições, sujeitos e contextos. Brasília: PNEPG-CNPq. 2001.

TRIVINŌS, A. N.S. Introdução a pesquisa em ciências sociais: pesquisa qualitativa. São Paulo: Atlas, 1987. 175 p.

UCHIMIRA, K. Y.; BOSI, M. L. M. A polissemia da qualidade na avaliação de programas e serviços de saúde resgatando a subjetividade. In: BOSI, M. L. M.; MERCADO, F. J. (Orgs.). Pesquisa qualitativa de serviços de saúde. Petrópolis: Vozes, 2004. p. 75-98.

VAITSMAN, J.; ANDRADE, G. R. B. Satisfação e responsividade: formas de medir a qualidade e a humanização da assistência à saúde. Ciências e Saúde Coletiva, Rio de Janeiro, v. 10, p. 599-613, 2005. VALDÉS-SALGADO, R.; MOLINA-LEZA, J.; SOLIS-TORRES, C. Aprender de lo sucedido. Análisis de las quejas presentadas ante la Comisión Nacional de Arbitraje Médico. Revista Salud Pública de México, v. 43, p. 444-54, 2001.

VUORI, H. V. Quality Assurance of Health Services: concepts and methodology. Copenhagen: WHO Regional office for Europa, 1982.

WORTHEN, B. R.; SANDERS, J. R.; FITZPATRICK, J. L. Avaliação de programas: concepção e práticas. São Paulo: Gente, 2004. 730p.

WEISS, G. L Patient satisfaction with primary medical care: evaluation of sociodemographic and predispositional factor. Med Care, v. 26, p. 383-392, 1988.

WILLIAMS, B. Patient satisfaction: a valid concept? Social Science and Medicine, v. 38, p. 509-51, 1994.

YÉPEZ, M. T.; MORAIS, N. A. Reivindicando a subjetividade dos usuários da rede básica de saúde: para uma humanização do atendimento. Cadernos de Saúde Pública, Rio de Janeiro, v. 20, p. 80-88, 2004. 


\section{Nota}

${ }^{1}$ Este texto é parte da dissertação de mestrado Atenção à saúde da criança e da gestante pelo Programa de Saúde da Família no município de Teixeiras-MG, financiada pelo CNPq (Processo no. 401905/055) e defendida em 2006 no Departamento de Nutrição e Saúde da Universidade Federal de Viçosa. 


\section{Abstract}

\section{Health Evaluation: Reflections on Contemporary Sanitary Paradigms}

This study presents a reflexive analysis on the health evaluation methods in the perspective of care conceived and performed according to the users' needs. There are several forms and approaches of the evaluative processes in search of a better apprehension of the object under evaluation. In this context, the user's satisfaction appears as an indicator for quality of health services, linked to better adaptation and promotion of real changes in health practices. Concerning the innovative proposal of the Family Health Program (PSF), based on the principles of integrality, reception, health care and humanization, the participation, the partnership and the users' satisfaction should be introduced as key elements in the formulation of their actions, therefore allowing changes in the hegemonic, healthcare model, that is positivistic, assistentialist and curativistic. The user's presence in the evaluation process will ensure a peculiar performance, remodeling health practices - probably making them more human, homelike, and consequently more resolutive.

- Key words: Health evaluation; users' satisfaction; evaluation methods; evaluation tools; Family Health Program. 